\title{
ESPASMO HEMIFACIAL
}

\author{
REGISTRO DE UM CASO
}

\section{J. HORTES-REGO *}

O espasmo hemifacial, cuja denominação escorreita e mais adequada parece-nos ser espasmo facial clônico unilateral - expressão que evita o emprego do prefixo grego indicativo de metade, e explicita a natureza do espasmo -, caracteriza-se pela ocorrência de contrações clônicas paroxísticas espontâneas em um ou vários músculos de um lado da face, geralmente começando pelo orbicular das pálpebras, estendendo-se em seguida, com predileção pelos músculos da comissura labial. Pode ocorrer como consequiência de uma paralisia facial ipsilateral que não evoluiu para a cura total, ou manifestar-se primariamente, isto é, em um nervo até então indene. É desta última forma de apresentação que hemos de ocupar-nos nesta oportunidade.

Em 1875 Schultze teria publicado o primeiro caso de espasmo facial clônico unilateral típico, cuja necropsia revelou um aneurisma da artéria vertebral comprimindo o sétimo nervo, e treze anos mais tarde Gowers, em sua clássica descrição dessa entidade, enfatizava o papel causal da pressão mecânica ${ }^{9}$. Nessa mesma ordem de idéias muitos outros trabalhos têm surgido, e a hipercinesia que ora nos ocupa aparece relacionada com neurinoma do acústico, tumor do ângulo pontocerebelar, aneurismas da artéria cerebelar posterior inferior $e$ outras más formações (ou mesmo estruturas vasculares normais) em contacto com o nervo facial, impressão basilar, doença de Paget, aracnoidite, encefalite e traumatismo 2,3,5,9,10. Destoando de todas essas, requer mencionada, como causa até certo ponto curiosa, a "psicopatologia" 3 . Maroon ${ }^{9}$ expõe três teorias que qualifica como as mais importantes quanto à etiologia: (1) a hipótese neurológica afirma que o processo patológico (de tipo inespecífico) situa-se no núcleo do facial ou no próprio nervo, próximo ao forámen estilomastóideo; (2) a teoria otológica postüla que a lesão causal (novamente de tipo indeterminado) consiste em edema ou constrição do nervo facial em seu curso através do osso temporal; (3) a hipótese neurocirúrgica estabelece que a sindrome é usualmente devida à compressão-distorção mecânica do facial por estruturas vasculares de tipo normal ou patológico e raramente por lesões expansivas. Consigne-se, alfim, o elevado número nos quais a etiologia permanece obscura, constituindo a forma "idiopática". Ehni e Woltman 4 encontraram, nos arquivos da Clínica Mayo, dez casos que tais.

Trabalho realizado no Departamento de Medicina Especializada da Faculdade de Ciências da Saúde da Universidade de Brasilia: * Professor de Neurologia. 
A individualização clínica do espasmo facial clônico unilateral no contexto dos movimentos involuntários da face é sumariada por Battisia 1 nos seguintes termos: os espasmos são intermitentes e limitados a músculos de um lado da face na dependência do sétimo nervo; as contrações usualmente envolvem as pálpebras e os músculos faciais superiores e inferiores; os movimentos não podem ser interrompidos voluntariamente e podem aparecer durante 0 sono ou durante anestesia; a tensão emocional freqüentemente exacerba a intensidade dos espasmos; finalmente, a doença não se manifesta em crianças. Todos esses atributos já haviam sido previamente ressaltados na literatura, como também o foram a indiscutivel predominância no sexo feminino e a facilidade com que os paroxismos são desencadeados pelos movimentos voluntários da face, notadamente ao falar.

No que concerne ao tratamento, a quase totalidade dos autores limita-se a discutir as diversas abordagens cirúrgicas. Os poucos que mencionam explicitamente o tratamento médico, invariavelmente atestam sua total ineficácia, a exemplo de Ehni e Woltman ${ }^{4}$ e Eckman e col. 3. Por outro lado, a multiplicidade das técnicas operatórias existentes parece indicar que, também aqui, a melhor solução dista de haver sido lograda; o denominador comum de praticamente todas é a agressão - maior ou menor - no nervo no ângulo pontocerebelar ou em sua porção extracraniana (veja-se em Gardner e Sava ${ }^{7}$ ).

\section{OBSERVAÇA}

L.M.S.B. (Reg. 213.280), com 28 anos de idade, sexo feminino, natural e procedente do Estado do Maranhão, e residente no Distrito Federal há 12 anos, consultou pela primeira vez o ambulatório de Neurologia do hospital universitário de Brasília em 13-10-83. Referiu que havia um mês vinha apresentando contraçõss no lado esquerdo do rosto surgidas poucos minutos depois de um banho quente de chuveiro após prolongada exposição aos raios solares entremeada por abluções em piscina com água fria. A freqüência dos episódios vinha aumentando, a ponto de, nos últimos dias que antecederam à consulta, não passar mais que 15 minutos livre da sintomatologia, que era despertada ou exacerbada com os movimentos voluntários, notadamente ao falar; idêntica influência era exercida pela emocão, enquanto as mudancas climáticas não pareciam modificá-la. Durante os curtos lapsos em que foi esporadicamente observada durante o sono não exibia os movimentos anormais. O interrogatório dirigido descortinou apenas, como dado de eventual interesse, a ocorrência de polidipsia e poliúris.. $O$ exame clínico geral era normal, o mesmo ocorrendo com o exame neurológico, excetuados os insistentes espasmos clônicos espontâneos que acometiam os músculos orbiculas e da comissura labial esquerdos (Fig. 1), e que escapavam ao controle da vontade. Exames complementares - Curva de tolerância à glicose: normal; EEG: traçào de baixo potencial com intensa interferência da atividade muscular a cargo dos slétrodos colocados nas áreas anteriores do hemicrânio esquerdo, a qual cessou completamente durante a hiperventilação pulmonar; EMG: «nervo facial com latência normal e os músculos orbicular do olho e orbicular dos lábios com potenciais neurogênicos (pobreza de unidades motoras)». Tratamento: foi instituida a carbamazepina, inicialmente $200 \mathrm{mg}$ 


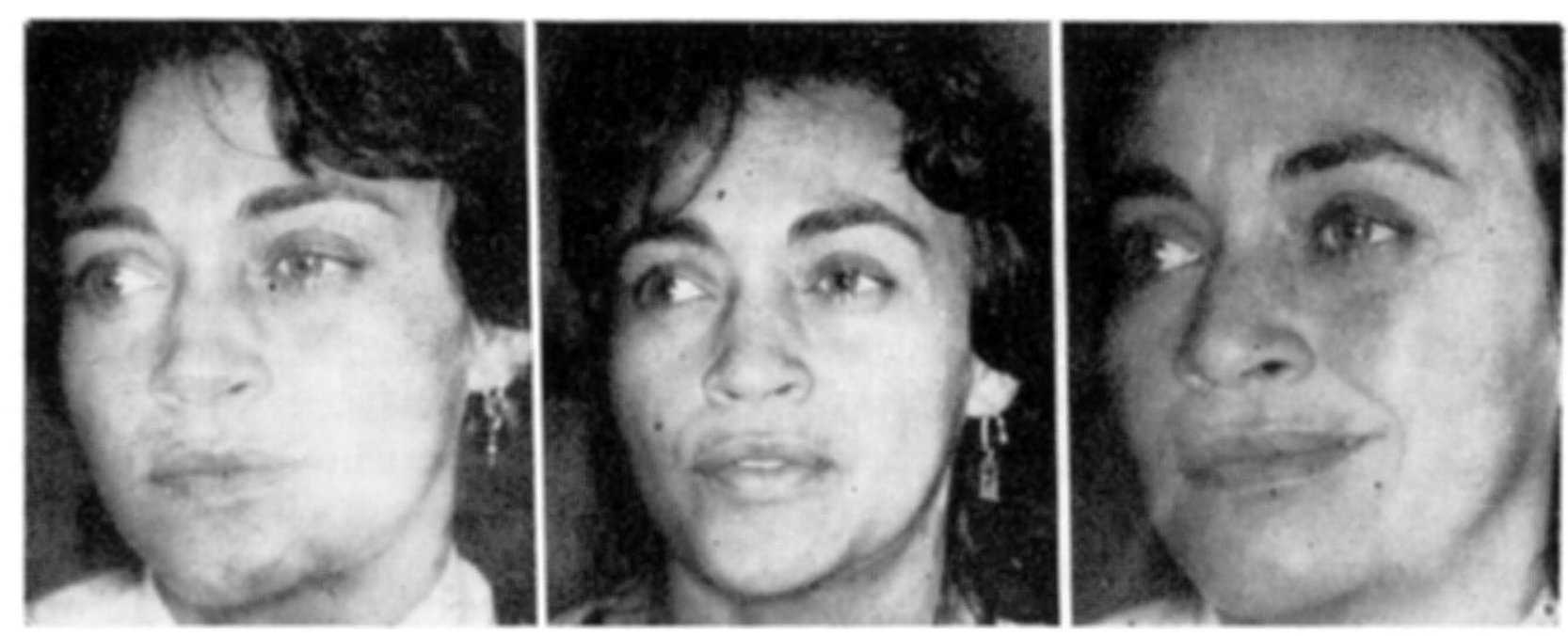

Eirg. 1 - Paciente L.M.S.B. apresentando espasmos clonicos espontaneos nos músculos orbicular e da comissura labial esquerdos.

de 12 em 12 horas, com o que se logrou uma resposta algo favorável logo nos primeiros dias; a partir do sexto dia, "a dose foi aumentada para $200 \mathrm{mg}$ de 8 em 8 horas, constatando-se a regressão dos espasmos após duas semanas.

\section{COMENTARIOS}

Embora o espasmo facial clônico unilateral seja considerado comum algures 5 , não parece sê-lo entre nós. Semelhante impressão firma-se em duas constatações: (a) no índice geral desta revista, compreendendo um período de quarenta anos, não há senão duas publicações pertinentes ao tema ${ }^{1,8}$; (b) por outro lado, no Distrito Federal, onde se registra inusitada prevalência de outra alteração do nervo - a paralisia facial periférica isolada ${ }^{6}$, é de todo insignificante a ocorrência do espasmo facial primário, numa proporção de menos de um caso deste para cada cem daquela. Destarte, parece justificada a presente comunicação. Ao demais, um outro aspecto suscita ainda maior interesse e merece ser discutido: a conduta terapêutica. Como vimos no início desta explanação, as dúvidas nesse particular soem restringir-se à modalidade de cirurgia a ser empregada, negando-se - implícita ou explicitamente - toda e qualquer eficácia ao tratamento conservador. Essa atitude niilista parece envolver até mesmo aqueles que aparentemente descrêem igualmente da validade da cirurgia. Seria o caso de Eckman e col. ${ }^{3}$, por exemplo, cujos quatro pacientes decidiram não ser operados, após serem esclarecidos quanto à natureza e prognóstico da doença e aos riscos de uma intervenção neurocirúrgica; ficou subentendido que tampouco foram submetidos a tratamento medicamentoso.

Em nossa paciente - descartada a hipótese inicial de diabete - a etiologia permanece obscura, e a resposta à carbamazepina pode ser considerada excelente até o momento. É óbvio que nenhuma conclusão pode surgir de um caso isolado, ainda mais quando o tratamento apenas se inicia; também não deve ser olvidada a possibilidade, embora muito remota, de remissão espontânea ${ }^{4,7}$. 
Contudo, não vislumbramos nenhum óbice, seja médico ou prático, para que a droga (eventualmente outra com propriedades farmacológicas semelhantes) seja invariavelmente ensaiada antes de qualquer procedimento cirúrgico, nada obstante a ausência de uma fundamentação científica, fato que não chega a constituir novidade no campo da Neurologia.

\section{RESUMO}

E apresentado o caso de uma moça de 28 anos de idade com espasmo facial clônico unilateral primário, cuja etiologia permanece obscurá. $O$ tratamento com a carbamazepina apresentou ótimo resultado, com regressão da sintomatologia em duas semanas.

\section{SUMMARY}

Hemifacial spasm: report of a case.

The author reports a case of a 28-year-old white girl who presented typical clonic spasm on the left side of the face without previous disorder of the facial nerve. No etiology could be determined. The treatment with carbamazepine has showed a very good response.

\section{REFERENCIAS}

1. BATTISTA, A.F. - Hemifacial spasm and blepharospasm. N.Y. State J. Med. $77: 2234,1977$.

2. CARVALHO, P.R.O.; OLIVEIRA, S.V. \& RODRIGUES, J.R.C. - Espasmo hemifacial: resultados do tratamento cirárgico em 14 casos. Arq. Neuro-Psiquiat.( São Paulo) 31:91, 1973.

3. FCKOMAN, P.B.; KRAMER, R.A. \& ALTROCCHI, P.H. - Hemifacial spasm. Arch. Neurol. (Chicago) 25:81, 1971.

4. EHNI, G. \& WOLTMAN, H. - Hemifacial spasm. Arch. Neurol. Psychiat. 53: 205, 1945.

5. FABINYI, G.C.A. \& ADAMS, C.B.T. - Hemifacial spasm: treatment by posterior fossa surgery. J. Neurol. Neurosurg. Psychiat. 41:829, 1978.

6. FORTES-RfGO, J. - Paralisia Facial Periférica Isolada: Uma Condicão Controversa. Diplomata Editora. Brasília, 1981. Distribuido pela Editora Pedagógica e Universitária - E.P.U. São Paulo.

7. GARDNER, W. \& SAVA, G.A. - Hemifacial spasm: a reversible pathophysiologic state. J. Neurosurg. 19:240, 1962.

8. JANNETTA, P.J.; ABBASY, M.; MAROON, J.C.; RAMOS, F.M. \& ALBIN, M.S. - Etiology and definitive microsurgical treatment of hemifacial spasm. J. Neurosurg. 47:321, 1977.

9. MAROON, J.C. - Hemifacial spasm. Arch. Neurol. (Chicago) 35:481, 1978.

10. MAROON, J.C.; LUNSFORD, L.D. \& DEEB, Z.L. - Hemifacial spasm due to aneurysmal compression of the facial nerve. Arch. Neurol. (Chicago) 35:545, 1978.

11. SAMPAIO, P. \& MACHADO, A. - Tratamento cirúrgico do espasmo hemifacial. Arq. Neuro-Psiquiat. (São Paulo) 33:52, 1975.

Universidade de Bnasilia - Departamento de Medicina Especializada - Disciplina de Neurologia - 70910, Brasilia, DF - Brasil. 